- Current guidance indicates intravenous conscious sedation shoulld not be used in children.

- Clinical experience, as presented in these cases, shows it can be a valuable management tool.

- Further research is required to ascertain the role of intravenous sedation in paediatric patients.

\title{
Intravenous conscious sedation in patients under 16 years of age. Fact or fiction?
}

\author{
N. D. Robb, ${ }^{1}$ M.-T. Hosey ${ }^{2}$ and J. A. Leitch, ${ }^{3}$
}

\begin{abstract}
Recently published guidelines on the use of conscious sedation in dentistry have published varying recommendations on the lower age limit for the use of intravenous conscious sedation. There are a large number of dentists currently providing dental treatment for paediatric patients under intravenous conscious sedation. The 18 cases reported here (age range 11-15 years), were successfully managed with intravenous conscious sedation. The experience in this paper is not sufficient evidence to recommend the wholesale use of intravenous conscious sedation in patients who are under 16 years. The fact that a range of operators can use these techniques on paediatric patients would suggest that further study should be carried out in this population. The guidance should be modified to say there is insufficient evidence to support the use of intravenous conscious sedation in children, rather than arbitrarily selecting a cut off point at age 16 years.
\end{abstract}

\section{INTRODUCTION.}

The use of intravenous conscious sedation in patients who are less than 16 years of age has been regarded as controversial. Recent guidance has varied between saying there is insufficient evidence to recommend the routine use for dentistry ${ }^{1}$ to suggestions that it should not be used except in a consultant led service in a hospital environment. ${ }^{2}$

Some of the evidence that is used to back up these assertions is misquoted. The Report of an Independent Working Party ${ }^{1}$ and the Academy of Medical Royal Colleges

\footnotetext{
${ }^{1 " S e n i o r ~ L e c t u r e r ~ i n ~ S e d a t i o n ~ i n ~ R e l a t i o n ~ t o ~ D e n t i s t r y, ~}$ University of Glasgow Dental School, ${ }^{2}$ Senior Lecturer in Paediatric Dentistry, University of Glasgow Dental School, ${ }^{3}$ Lecturer in Oral Surgery, University of Glasgow Dental School

"Correspondence to: N. D. Robb, 378 Sauchiehall Street, Glasgow G2 3JZ

Email:n.robb@dental.gla.ac.uk
}

\section{Refereed Paper}

Received 10.07.02; Accepted 13.02.03

( ) British Dental Journal 2003; 194: 469-471 report ${ }^{3}$ is used to support the use of intravenous conscious sedation in hospital for child patients, ${ }^{2}$ but neither document makes any such recommendation.

The confusion in the guidelines results from the fact that there is actually very little evidence to either support or condemn or refute the use of intravenous conscious sedation in patients under the age of 16 years.

Informal approaches by the authors to other clinicians involved in teaching conscious sedation revealed that many clinicians do use intravenous conscious sedation in patients who are under 16 years, provided that a full assessment of the patient indicates that this would be the most appropriate management technique.

\section{AIM}

This paper reports a number of cases of children aged between 11 and 15 who have been successfully managed under intravenous conscious sedation. It aims to show that where appropriate, conscious sedation can be used safely and effectively in these patients. The authors wish to present some evidence to open the debate on how to effectively manage paediatric dental patients, especially when alternatives to general anaesthesia are being sought.

\section{THE PATIENTS}

The sedation teaching facilities at Liverpool, Cardiff and Glasgow Dental Schools carried out a retrospective trawl through the appointment books for the academic year 2001-2002 and reported cases where children between the ages of 11 and 15 years were treated. Two cases treated as demonstrations on a course in Germany were also included.

The cases presented are a selected sample of paediatric patients referred for care where the assessing clinician has judged that intravenous conscious sedation was the most appropriate form of anxiety management. 
The sedation technique used, dental treatment carried out and any complications were noted. The centres were asked whether the patients had been starved prior to treatment. All of the patients, except those treated in Germany, and three in Glasgow had been allowed to eat until at least two hours before treatment.

\section{OUTCOME OF TREATMENT}

The results are shown in Table 1. All of the patients were successfully treated. The outcome was judged to be successful when the patient was able to co-operate with dental treatment without becoming distressed. Dental undergraduate students treated six of the 18 children as part of their training, while staff treated another six with undergraduate students observing. Cases 13 and 14 were sedated by one of the authors (NDR) as part of a course run in Germany for German dentists.

Patients 15 and 16 required exposure of unerupted maxillary canine teeth. Trainees in surgical dentistry undergoing training in sedation techniques treated these patients.

A consultant in paediatric dentistry assisted by a consultant anaesthetist treated patients 17 and 18 . This reflected the purpose of this list that mixed anxious adolescents with learning disability adults requiring general anaesthesia.

In all cases the patients were conscious throughout the procedure according to the General Dental Council definition. In other words all patients responded to verbal command.

Eight of the patients had treatment over multiple appointments, and all were happy to receive intravenous sedation having experienced it before. None of the parents returning with their children reported any problems in the postoperative treatment other than tiredness and bruising at the site of venepuncture.

Table 1 records the doses of total doses of midazolam used. In the case of patients who were sedated on more than one occasion the range represents the maximum and minimum doses given during the series of appointments. The dose of midazolam was titrated according to standard protocols. ${ }^{4}$

\section{DISCUSSION}

These patients were successfully managed with intravenous conscious sedation. Dental undergraduate students working under supervision treated about half of the patients. There were no problems with unexpected loss of consciousness, or falls in arterial oxygen saturation that might be explained by the sedation becoming unpredictably deeper than desired. None of these children were disinhibited by intravenous midazolam.

The German patients were having prophylactic wisdom tooth removal, as recommended by the orthodontist who was treating them. The German patients, while still able to talk to the surgeon in German throughout the procedure, lost the ability to understand English instructions at a point before a satisfactory level of sedation could be achieved. Care should be taken when managing patients whose first language is not spoken by the sedationist, as communication between patient and sedationist may become diffi- cult. It would appear that the patients are so relaxed that they will not make the effort to understand a foreign language.

The range of operators who successfully managed these patients indicates that the outcome is not merely related to a single clinician who happens to be exceptionally gifted in the management of paediatric dental patients under intravenous conscious sedation.

There were no problems associated with the patients having eaten up to two hours before the appointment. The recent guidelines have suggested that patients should be starved for up to 6 hours. ${ }^{2}$ There is no justification for this view in the literature, and further research is required to establish the correct regime for pre-operative eating. It is the authors' opinion that the protracted starving of patients is not only unnecessary, but is also counterproductive. Long periods without food make children more irritable, and may increase the likelihood of fainting. It should thus be avoided if it does not increase the safety of patient management.

The number of cases reported here is insufficient to provide evidence to support the routine use of this technique. The patients presented are all adolescents (age range 11-15), and thus this paper should not be used as a justification for patients outside this age group.

The cases presented cannot be considered as a random or representative sample of all 11 to 16 year olds requiring dental treatment, and who are anxious about receiving care. They have all been assessed as suitable for intravenous conscious seda-

\begin{tabular}{|c|c|c|c|c|c|c|c|c|}
\hline Study number & Age at time of treatment & Sex & Number of appointments & Drug used & Dose or range & Type of treatment & ht (if known) & Coments \\
\hline 1 & $11-12$ & $\mathrm{~F}$ & 5 & Midazolam & $3-4 \mathrm{mg}$ & Cons & - & Previous Failed RA \\
\hline 2 & 14 & $\mathrm{~F}$ & 5 & Midazolam & $4-8 \mathrm{mg}$ & Cons + XLA & $61.8 \mathrm{~kg}$ & Coped very well \\
\hline 3 & 14 & M & 2 & Midazolam & $6-7 \mathrm{mg}$ & $X L A$ & - & - \\
\hline 4 & 14 & $\mathrm{~F}$ & 1 & Midazolam & $8 \mathrm{mg}$ & Ortho XLA & - & Second molars \\
\hline 5 & 14 & $\mathrm{~F}$ & 1 & Midazolam & $7 \mathrm{mg}$ & $X L A$ & $47.3 \mathrm{~kg}$ & - \\
\hline 6 & 14 & $\mathrm{~F}$ & 5 & Midazolam & $6-8 \mathrm{mg}$ & Cons + XLA & $61.9 \mathrm{~kg}$ & Coped very well \\
\hline 7 & 14 & M & 2 & Midazolam & $6 \mathrm{mg}$ & Endo & - & Uneventful \\
\hline 8 & 14 & $\mathrm{~F}$ & 5 & Midazolam & $8-10 \mathrm{mg}$ & Crowns and cons & - & Uneventful \\
\hline 9 & 12 & - & 1 & Midazolam & $10 \mathrm{mg}$ & $X L A$ & - & - \\
\hline 10 & 13 & - & 2 & Midazolam & $10 \mathrm{mg}$ & OrthoXLA & - & Uneventful \\
\hline 11 & 14 & - & 1 & Midazolam & $6 \mathrm{mg}$ & Cons & - & - \\
\hline 12 & 15 & $\mathrm{~F}$ & 2 & Midazolam & $5 \mathrm{mg}$ & Cons & - & - \\
\hline 13 & 15 & M & 1 & Midazolam & $7 \mathrm{mg}$ & Removal of wisdom teeth & $70 \mathrm{~kg}$ & No problems \\
\hline 14 & 14 & M & 1 & Midazolam & $6 \mathrm{mg}$ & Removal of wisdom teeth & $56 \mathrm{~kg}$ & $\begin{array}{l}\text { Slight reaction to } \\
\text { ID Nerve block }\end{array}$ \\
\hline 15 & 13 & $\mathrm{~F}$ & 1 & Midazolam & $4 \mathrm{mg}$ & $X L A+$ Exposure of canines & s- & $\begin{array}{l}\text { Excellent co-operation. } \\
\text { Fasted pre-op }\end{array}$ \\
\hline 16 & 15 & $\mathrm{~F}$ & 1 & Midazolam & $6 \mathrm{mg}$ & $X L A+$ Exposure of canines & s - & $\begin{array}{l}\text { Coped very well } \\
\text { Fasted pre-op }\end{array}$ \\
\hline 17 & 13 & M & 2 & Midazolam & $5 \mathrm{mg}$ & Premolar extractions & - & uneventful \\
\hline 18 & 13 & M & 1 & Midazolam & $9 \mathrm{mg}$ & Traumatised tooth & - & uneventful \\
\hline
\end{tabular}


tion by the treating clinician, and are thus a selected group.

The authors would suggest that there is sufficient doubt as to the validity of the current recommendations prohibiting the use of intravenous conscious sedation in adolescents to justify further research into its use in this age group of patients.

\section{CONCLUSION}

Further research into the use of intravenous conscious sedation in patients under the age of 16 is required. There is insufficient evidence currently available to support the routine use of conscious sedation in this age group, but equally there is sufficient doubt to make an absolute prohibition of the use of these techniques in this age group of patients unjustifiable.

The authors would like to thank Dr Shelagh Thompson, Dr Lesley Longman, and Dr Wolfgang Jakobs for helping with the provision of data for this paper.
1. Standards in Conscious Sedation for Dentistry. Report of an Independent Expert Working Group. October 2000.

2. Safe Sedation of Children Undergoing Diagnostic and Therapeutic Procedures. A national clinical guideline. Scottish Intercollegiate Guidelines Network. February 2002

3. Implementing and Ensuring Safe Sedation Practice for Healthcare Procedures in Adults. Report of an Intercollegiate Working Party chaired by the Royal College of Anaesthetists. Academy of Medical Royal Colleges. November 2001.

4. Meechan J G, Robb N D, Seymour R A. Pain and Anxiety Control for the Conscious Dental Patient Oxford: Oxford University Press, 1998 pp 282-285.

\section{BDA launches clinical seminars series}

The BDA and BDJ are launching a new series of clinical seminars based on the BDJ's bestselling and authoritative Clinical Guide Series. Seminars will be held throughout the UK and will give dentists the opportunity to work with clinical leaders on a range of exciting topics highly relevant to today's dental practice.

The first seminar will take place on Saturday 17th May 2003 at The General Dental Council, London with the programme being repeated in November in association with the Western Counties Branch.

Speakers at the seminars, 'Removable Partial Dentures: Planning, Communicating and Making' will be two of the authors of the BDJ book 'A Clinical Guide to Removable Partial Dentures', Professor Robin Basker and Jim Ralph. The aims and objectives of the day are:

- To highlight the factors which influence the decision whether or not to provide a partial denture and to consider the idea of fewer, better dentures.

- To provide an opportunity for hands-on treatment planning and design followed by discussion of delegates' opinions.

- To present the available evidence on how dentists communicate with dental technicians and to consider the role of the computer in communication.

- To consider the principles of denture design which promote good oral health

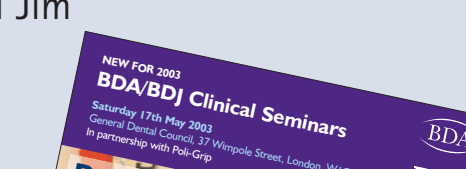
and which lead to the construction of stable dentures for common situations.

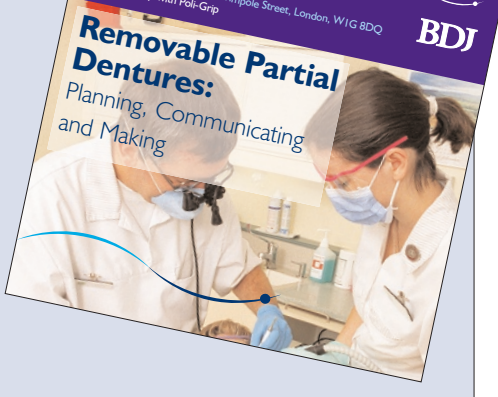

- To demonstrate impression techniques for the sublingual bar and for lower distal extension saddles.

- To discuss the role of the RPD in managing the growing problem of tooth surface loss.

The seminar is aimed at dentists and their team including dental technicians and will be limited to 80 so you are advised to book early to avoid disappointment. The day will involve group work on treatment planning cases which will be illustrated by a history, coloured photos, radiographs and study casts.

Fees: Members: Ł230; Non-Members: Ł265; Staff/Dental Technicians: $€ 150$

Further information: Further information on all BDA events can also be seen at www.bda-events.org.uk where you may also now book on-line. You may also book by contacting Katherine Fort on 02075634166. 